\title{
Measuring parent proxy-reported quality of life of 11 rare diseases in children in Zhejiang, China
}

\author{
Qisheng Gao ${ }^{1}$, Shanshan Wang ${ }^{2}$, Jianping Ren ${ }^{2}$ and Xin Wen ${ }^{3^{*}}$
}

\begin{abstract}
Background: It has become increasingly important to measure the health-related quality of life (HRQoL) of rare diseases in children and adolescents in recent decades. Much attention has been paid to investigate the HROoL of a specific rare disease by self-report in previous studies. This study aimed to evaluate and compare the HROoL of 11 rare diseases in Chinese children by parent proxy-report, to explore the factors associated with HROOL of patients, and to understand the problems of most concern.

Methods: A total of 651 children aged from 2 to 18 were enrolled from the Children's Hospital Affiliated Zhejiang University in 2018. Their parents completed the parent proxy-report version of the Pediatric Quality of Life Inventory ${ }^{\mathrm{TM}}$ 4.0 (PedsQL ${ }^{\mathrm{TM}}$ 4.0). Independent samples $t$-test, one-way ANOVA, or Kruskal-Wallis $H$ test was used to compare HROoL scores between groups. Multilevel linear regression models with random intercept were applied to analyze the relationship between socioeconomic variables and both the total score and subdomain scores.

Results: The total PedsQL scores of Patent ductus arteriosus (PDA), Infantile agranulocytosis, Autoimmune thrombocytopenia (ITP), Polysyndactyly, Hirschsprung disease, Cleft lip and palate, Tetralogy of fallot, Myasthenia gravis, Guillain-barre syndrome, Glycogen storage disease, and Langerhans cell histiocytosis children were 79.65 \pm 5.46 , $95.88 \pm 3.48,71.39 \pm 3.27,91.77 \pm 6.35,76.18 \pm 6.92,96.33 \pm 4.22,77.85 \pm 8.90,95.99 \pm 3.31,85.77 \pm 4.56,82.97 \pm 4.13$ and $77.6 \pm 5.15$, respectively. Age was significantly associated with physical functioning, school functioning, and psychosocial health scores. The household registration place was significantly related to the total score. The most urgent desire of patients was to reduce the overall medical costs.

Conclusions: This study showed that patients with PDA had the lowest physical functioning score, while patients with ITP scored the lowest in the emotional functioning, social functioning, school functioning, psychosocial health, and total scores. Incentive policies should be further adopted to improve orphan drug availability and reduce the economic burden of rare diseases.
\end{abstract}

\section{Background}

Rare diseases, also known as "orphan diseases", refer to diseases with a low prevalence but which are seriously debilitating or even life-threatening [1]. There is no

\footnotetext{
*Correspondence: kjwx9668@163.com

${ }^{3}$ Center for Medical Science, Technology and Education of Zhejiang Province, No, 60 Hefang Street, Hangzhou 310006, Zhejiang Province, China

Full list of author information is available at the end of the article
}

universal definition of rare diseases worldwide. Different countries or regions have distinct definitions depending on disease incidence or prevalence, the severity of the disease, and the existence of adequate treatments or drugs. The average prevalence threshold used to define rare diseases across different organizations within individual jurisdictions ranges from 5 to 76 cases/100,000 people, with a global average prevalence threshold of 40 cases/100,000 people [2]. In China, rare diseases have not original author(s) and the source, provide a link to the Creative Commons licence, and indicate if changes were made. The images or other third party material in this article are included in the article's Creative Commons licence, unless indicated otherwise in a credit line to the material. If material is not included in the article's Creative Commons licence and your intended use is not permitted by statutory regulation or exceeds the permitted use, you will need to obtain permission directly from the copyright holder. To view a copy of this licence, visit http://creativecommons.org/licenses/by/4.0/. The Creative Commons Public Domain Dedication waiver (http://creativeco mmons.org/publicdomain/zero/1.0/) applies to the data made available in this article, unless otherwise stated in a credit line to the data. 
been officially defined until now. In 2010, experts in the seminar held by the Chinese Society of Genetic Medicine of the Chinese Medical Association reached a consensus that a rare disease was defined as the prevalence of less than $1 / 500,000$ or neonatal morbidity of less than $1 / 10,000$. It is estimated to exceed 16.8 million rare disease patients in China with a population of 1.4 billion according to this prevalence [3]. There are an estimated $6000-8000$ rare diseases worldwide [4], $75 \%$ of rare diseases affect children, and $30 \%$ of rare diseases patients die before the age of 5 [5]. In 2018, the National Health Commission of China and other 4 government departments jointly formulated and published China's First List of Rare Diseases, including 121 rare diseases [6]. The onset age of 43 rare diseases are during an infant and child's stage, such as Albinism, Angelman syndrome, Arginase deficiency and so on. Most rare diseases are the result of small genetic changes and can severely impair physical, emotional, and mental abilities. These disabilities can decrease the quality of life considerably and cause a tremendous burden on the affected families and health care systems [7]. In recent decades, it has become increasingly important to measure the health-related quality of life (HRQoL) of rare diseases in children and adolescents. Generic instruments and disease-specific instruments may be applied to measure HRQoL in children and adolescents with the same rare diseases [8]. The generic instruments can measure HRQoL domains across diseases and can be used in different populations [9]. Among the generic instruments, the Pediatric Quality of Life Inventory ${ }^{\mathrm{TM}}$ (PedsQL ${ }^{\mathrm{TM}}$ ) is one of the widely used instruments in young people [10]. To evaluate patients' HRQoL, many previous studies randomly selected healthy controls subjects for comparisons [11-14]. However, there is a paucity in the literature documenting differences in HRQoL among different rare diseases.

The main purpose of this study was to evaluate and compare HRQoL by surveying the parents of children with 11 different rare diseases between the ages of 2 and 18 by using the PedsQL ${ }^{\mathrm{TM}}$ instrument which can assess the domains outlined by WHO [15], to identify the association between potentially confounding factors on the HRQoL summary scores, and to understand the issues that patients are most concerned about.

\section{Methods}

\section{Participants and procedures}

The study was a cross-sectional, observational study performed in 2018 in the Children's Hospital affiliated to Zhejiang University. The hospital we investigated is the highest-level children's hospital in the region, which can reduce misdiagnosis and missed diagnosis to some extent. Besides, the diagnosis of patients was confirmed by the doctor, and the screened cases were all hospitalized cases, so the accuracy of diagnosis was relatively high. We signed a confidentiality agreement with the hospital to ensure that the patient's information will be kept strictly confidential. Patients diagnosed with rare diseases included in the List of Rare Diseases in the European Union during the period 2013-2017 were recruited from the hospital [16]. The criteria for inclusion were as follows: (1) The age of patients was between 2 and 18 years old; (2) The patients were diagnosed with no other diseases severely affecting the quality of life; (3) The parents were capable of understanding and expressing normally; (4) Consent of parents. The exclusion criteria were as follows: (1) Patients were younger than 2 years or older than 18 years at the time of interview; (2) Patients had other unrelated serious diseases. The parents were informed of the purpose, significance, and main content of the investigation orally before the telephone interview, and asked for their consent. The investigators were trained before the interview by the project manager to be very familiar with the questionnaire and use the normative expression. Besides, the investigators were responsible for ensuring that there were no missing data or logical errors in the questionnaire.

\section{Instruments}

The Pediatric Quality of Life Inventory ${ }^{\text {TM }} 4.0$ (Ped$\mathrm{SQL}^{\mathrm{TM}} 4.0$ ), which includes parallel child self-report (age range 5-18 years) and parent proxy-report (age range 2-18 years), is a reliable, valid and sensitive instrument for widely used to assess HRQoL in the health and patient populations [17, 18]. While child self-report should be considered the gold standard for measuring HRQoL, in some cases, due to mental or cognitive impairment, or the lack of instruments for specific diseases, children may not be able to complete the questionnaire directly, and parent proxy-report may be a strategy for assessing children or adolescents' HRQoL [19, 20]. The items for child self-report and parent proxy-report are basically consistent, except that they differ in the developmentally appropriate language and the first or third person tense $[17,21]$. Previous empirical studies have confirmed the validity of parental reports [22, 23]. Besides, it is generally the parents' perceptions of their children's HRQoL that influence healthcare utilization [24, 25]. In this study, the Chinese parent proxy-report version of the PedsQL ${ }^{\mathrm{TM}} 4.0$ which has been validated in Chinese children was applied to evaluate children's quality of life [2629]. This scale consists of 23 items, which are divided into 4 dimensions: Physical functioning (8 items), Emotional functioning (5 items), Social functioning (5 items) and School functioning ( 5 items). The latter 3 dimensions can also be united, called psychosocial health. Each item was 
scored using a 5-point response scale, of which $0=$ never a problem, $1=$ almost never a problem, $2=$ sometime a problem, $3=$ often a problem, $4=$ almost always a problem. The items were reverse-scored and linearly converted to a score of $0-100(0=100,1=75,2=50,3=25$, $4=0)$ with higher scores indicated better HRQoL. The scale scores were computed as a sum of the items divided by the number of items answered. If more than $50 \%$ of the items in the scale were missing, the scale score would not be calculated.The physical, emotional, social, school, psychosocial, and total scores were used in this study. In addition to PedsQL ${ }^{\mathrm{TM}}$ 4.0, all parents were required to complete a brief questionnaire covering the children's socio-demographic characteristics, such as gender, age group, household registration place, household type, and monthly family income per capita.

\section{Statistical analysis}

Categorical data were presented as counts and percentages. Quantitative data were described by mean and standard deviation. The distribution of the HRQoL scores was tested for normality using the Shapiro-Wilk test. Comparisons between two groups were made using independent $t$-test. When there were more than two groups, the differences were evaluated by one-way ANOVA and Kruskal-Wallis $H$ test according to the homogeneity of variance.

Multiple comparisons were made by Dunn's post hoc test or least significant difference test (LSD). The multilevel linear regression models with random intercept were applied to analyze the relationship between socioeconomic variables and total score and subdomain scores. Initially, a model was estimated with the intercept only to estimate the proportion of variance due to the diseases concerning the individuals. This model served as the basis for evaluating the reduction in the variance of other models studied. After this, individual socioeconomic variables were tested. The two-tailed $P<0.05$ was considered to be statistically significant. Data were processed and analyzed using R 3.6.1 for windows.

\section{Results}

\section{Participants' characteristics}

A total of 651 children's parents completed the questionnaire. The socio-demographic characteristics of their children were presented in Table 1 . The most frequently presenting rare disease was ITP (18.4\%). Among the children, 373 (57.3\%) were male, 310 (47.6\%) aged between 2 to 4 years, $474(72.8 \%)$ came from urban areas, and 288 (44.2\%) of the monthly family income per capita less than $5000 \mathrm{CNY}$. These children came from 9 cities in Zhejiang province. They were 350 (53.8\%) from Hangzhou, 105 (16.1\%) from
Ningbo, 67 (10.3\%) from Shaoxing, 25 (3.8\%) from Wenzhou, 51 (7.8\%) from Jinhua, 10 (1.5\%) from Lishui, 29 (4.5\%) from Quzhou, 11 (1.7\%) from Taizhou and 3 (0.5\%) from Zhoushan. Due to the discrepancy of sample size in different cities, except the provincial capital city of Hangzhou, the other 8 cities were integrated into a group.

\section{PedsQL scores of children}

Univariate analysis of categorical variables relative to PedsQL total score and subdomain scores were summarized in Table 2. There were significant differences in the total scale and each subscale in different rare diseases, household registration place, and monthly family income per capita (all $P<0.05$ ). The physical functioning score of children with Patent ductus arteriosus (PDA) was significantly lower than that of children with Infantile agranulocytosis, Polysyndactyly, Hirschsprung disease, Cleft lip and palate, and Myasthenia gravis (all $P<0.05)$. The emotional functioning, school functioning and total scores of ITP were significantly lower than those of other rare diseases except Langerhans cell histiocytosis (all $P<0.05$ ). The social functioning score of ITP was significantly lower than that of other rare diseases except Hirschsprung disease (all $P<0.001$ ), and the psychosocial health score of ITP was significantly lower than that of other rare diseases (all $P<0.001$ ). Females reported significantly higher scores than male in the physical functioning score $(t=-3.29, P=0.001)$ and total score $(t=-2.43, P=0.015)$. The $2-4$ year group was significantly higher than the 8-12 year group in the emotional functioning score $(t=2.917$, $P=0.004)$. The $2-4$ year group was significantly higher than the $5-7$ year group $(Z=2.979, P=0.017)$ and the 8-12 year group $(Z=5.512, P<0.001)$ in the school functioning score. The 8-12 year group was significantly lower than other age groups in the psychosocial health score (all $P<0.05$ ). The $2-4$ year group was significantly higher than the $8-12$ year group $(Z=3.436$, $P=0.004)$ in the total score. The scores of subscale and total scale of children with household registration place in Hangzhou were higher than those of children with household registration place in other cities (all $P<0.001)$. Children in urban areas reported significantly higher scores than children in rural areas in physical functioning score $(t=3.31, P=0.001)$, school functioning score $(t=3.24, P=0.001)$,psychosocial health score $(t=2.45, P=0.015)$ and total score $(t=3.05, P=0.002)$. The total score and each subdomain score of the children with family monthly income per capita over $10,000 \mathrm{CNY}$ were significantly higher than those of the low-income groups (all $P<0.05$ ). 


\section{Factors associated with $\mathrm{HRQ}$ oL}

The multilevel linear regression models were shown in Table 3 . The physical functioning score of 8-12-year-old children was higher than that of 2-4-year-old children $(P<0.001)$. The score of school functioning decreased with the increase of children's age $(P<0.05)$. The psychosocial health score of 8-12-year-old children was lower than that of $2-4$-year-old children $(P=0.019)$. The total score of children whose household registration place was in Hangzhou was higher than that of children in other cities $(P=0.027)$.

\section{Reimbursement rates and the most urgent desires}

The reimbursement rates of medical insurance for rare diseases were set to four grades: $0-20 \%, 20-40 \%$, $40-60 \%, 60-80 \%, \geq 80 \%$. The proportion of patient who chose these four levels were $47.2 \%, 30.1 \%, 17.2 \%, 4.9 \%$ and $0.6 \%$, respectively. The choice proportions of the most urgent desires were $28.2 \%, 21.1 \%, 18.3 \%, 15.5 \%, 14.4 \%$, and $2.5 \%$ for a decrease in overall medical costs, improve diagnosis and treatment techniques, increase reimbursement rate, improve drug availability, service organizations can provide nursing services, not be discriminated at school, respectively (Fig. 1).

\section{Discussion}

In the current study, we used the parent proxy-report version of the PedsQL ${ }^{\mathrm{TM}} 4.0$ instrument to assess and compare the quality of life of patients with 11 rare diseases. Many studies proved that there was no statistically significant difference between child self-report and parent-proxy report of the PedsQL ${ }^{\mathrm{TM}} 4.0$ scales, and moderate to good concordance was found between the child and parent-proxy scores [8, 15, 30-33]. However, other studies showed inconsistencies between parentproxy and child self-report of HRQoL, especially in the
Table 1 Socio-demographic characteristics of the total participants

\begin{tabular}{|c|c|}
\hline Variables & Frequency (\%) \\
\hline \multicolumn{2}{|l|}{ Types of rare diseases } \\
\hline Patent ductus arteriosus & $40(6.1)$ \\
\hline Infantile agranulocytosis & $67(10.3)$ \\
\hline Autoimmune thrombocytopenia & $120(18.4)$ \\
\hline Polysyndactyly & $66(10.1)$ \\
\hline Hirschsprung disease & $118(18.1)$ \\
\hline Cleft lip and palate & $51(7.8)$ \\
\hline Tetralogy of fallot & $56(8.6)$ \\
\hline Myasthenia gravis & $42(6.5)$ \\
\hline Guillain-barre syndrome & $33(5.1)$ \\
\hline Glycogen storage disease & $30(4.6)$ \\
\hline Langerhans cell histiocytosis & $28(4.3)$ \\
\hline \multicolumn{2}{|l|}{ Gender } \\
\hline Male & $373(57.3)$ \\
\hline Female & $278(42.7)$ \\
\hline \multicolumn{2}{|l|}{ Age group } \\
\hline 2-4 year & $310(47.6)$ \\
\hline $5-7$ year & $220(33.8)$ \\
\hline $8-12$ year & $103(15.8)$ \\
\hline 13-18 year & $18(2.8)$ \\
\hline \multicolumn{2}{|l|}{ Household registration place } \\
\hline Hangzhou & $350(53.8)$ \\
\hline Other cities & $301(46.2)$ \\
\hline \multicolumn{2}{|l|}{ Household type } \\
\hline Urban areas & $474(72.8)$ \\
\hline Rural areas & $177(27.2)$ \\
\hline \multicolumn{2}{|l|}{ Family monthly income per capita } \\
\hline$<¥ 5000$ & $288(44.2)$ \\
\hline$¥ 5000-¥ 10,000$ & $259(39.8)$ \\
\hline$>¥ 10,000$ & $104(16.0)$ \\
\hline Total & $651(100)$ \\
\hline
\end{tabular}

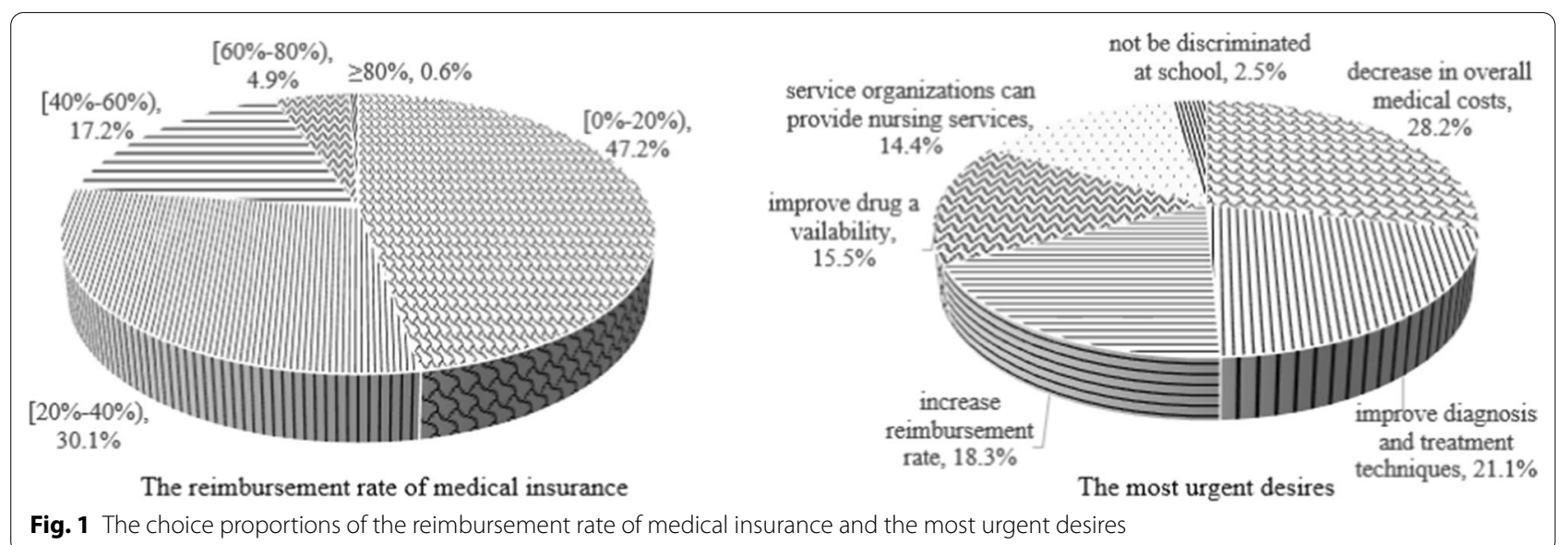


Table 2 Comparisons of PedsQL scores reported by parents

\begin{tabular}{|c|c|c|c|c|c|c|}
\hline Variables & Physical functioning & $\begin{array}{l}\text { Emotional } \\
\text { functioning }\end{array}$ & Social functioning & School functioning & Psychosocial health & Total \\
\hline \multicolumn{7}{|l|}{ Types of rare diseases } \\
\hline $\begin{array}{l}\text { Patent ductus arte- } \\
\text { riosus }\end{array}$ & $65.86 \pm 8.88$ & $84.38 \pm 8.18$ & $87.75 \pm 8.91$ & $88.88 \pm 8.95$ & $87.00 \pm 6.16$ & $79.65 \pm 5.46$ \\
\hline $\begin{array}{l}\text { Infantile agranulo- } \\
\text { cytosis }\end{array}$ & $97.01 \pm 3.86$ & $94.93 \pm 6.18$ & $97.76 \pm 5.02$ & $93.13 \pm 9.8$ & $95.27 \pm 4.55$ & $95.88 \pm 3.48$ \\
\hline $\begin{array}{l}\text { Autoimmune throm- } \\
\text { bocytopenia }\end{array}$ & $73.33 \pm 4.72$ & $73.04 \pm 6.16$ & $75.75 \pm 3.47$ & $62.25 \pm 7.21$ & $70.35 \pm 3.81$ & $71.39 \pm 3.27$ \\
\hline Polysyndactyly & $90.39 \pm 9.76$ & $91.59 \pm 9.49$ & $94.09 \pm 7.99$ & $91.82 \pm 9.27$ & $92.50 \pm 6.78$ & $91.77 \pm 6.35$ \\
\hline Hirschsprung disease & $74.84 \pm 10.44$ & $78.56 \pm 8.80$ & $77.84 \pm 10.16$ & $74.28 \pm 10.38$ & $76.89 \pm 7.20$ & $76.18 \pm 6.92$ \\
\hline Cleft lip and palate & $99.02 \pm 2.38$ & $96.47 \pm 6.35$ & $92.75 \pm 11.42$ & $95.49 \pm 7.09$ & $94.9 \pm 6.160$ & $96.33 \pm 4.22$ \\
\hline Tetralogy of fallot & $72.38 \pm 11.8$ & $80.54 \pm 10.77$ & $84.38 \pm 11.64$ & $77.41 \pm 9.72$ & $80.77 \pm 8.72$ & $77.85 \pm 8.90$ \\
\hline Myasthenia gravis & $96.58 \pm 4.72$ & $94.29 \pm 5.90$ & $98.69 \pm 3.83$ & $94.05 \pm 7.90$ & $95.67 \pm 3.97$ & $95.99 \pm 3.31$ \\
\hline $\begin{array}{l}\text { Guillain-barre syn- } \\
\text { drome }\end{array}$ & $74.34 \pm 10.39$ & $86.21 \pm 8.48$ & $96.52 \pm 5.23$ & $92.88 \pm 4.68$ & $91.87 \pm 3.25$ & $85.77 \pm 4.56$ \\
\hline $\begin{array}{l}\text { Glycogen storage } \\
\text { disease }\end{array}$ & $76.15 \pm 6.69$ & $85.50 \pm 9.04$ & $90.33 \pm 6.81$ & $84.00 \pm 8.14$ & $86.61 \pm 4.58$ & $82.97 \pm 4.13$ \\
\hline $\begin{array}{c}\text { Langerhans cell } \\
\text { histiocytosis }\end{array}$ & $73.10 \pm 10.74$ & $79.29 \pm 11.44$ & $90.89 \pm 8.50$ & $69.82 \pm 8.44$ & $80.00 \pm 5.72$ & $77.60 \pm 5.15$ \\
\hline$x^{2}$ & $400.95^{*}$ & $338.69^{*}$ & $371.83^{*}$ & $430.23^{*}$ & $471.05^{*}$ & $483.00^{*}$ \\
\hline$P$ & $<0.001$ & $<0.001$ & $<0.001$ & $<0.001$ & $<0.001$ & $<0.001$ \\
\hline \multicolumn{7}{|l|}{ Sex } \\
\hline Male & $79.41 \pm 13.45$ & $83.67 \pm 11.24$ & $86.42 \pm 11.63$ & $80.44 \pm 14.72$ & $83.51 \pm 10.86$ & $82.08 \pm 10.51$ \\
\hline Female & $82.94 \pm 13.65$ & $84.98 \pm 11.85$ & $87.59 \pm 11.77$ & $81.94 \pm 15$ & $84.84 \pm 11.25$ & $84.18 \pm 11.12$ \\
\hline$t$ & -3.29 & -1.44 & -1.26 & -1.28 & -1.52 & -2.43 \\
\hline$P$ & 0.001 & 0.151 & 0.207 & 0.202 & 0.130 & 0.015 \\
\hline \multicolumn{7}{|l|}{ Age group } \\
\hline 2-4 year & $81.99 \pm 14.39$ & $85.45 \pm 11.5$ & $86.87 \pm 12.43$ & $83.92 \pm 13.81$ & $85.41 \pm 10.78$ & $84.22 \pm 10.98$ \\
\hline 5-7 year & $80.24 \pm 13.08$ & $83.64 \pm 11.87$ & $87.11 \pm 10.86$ & $79.93 \pm 15.59$ & $83.56 \pm 11.35$ & $82.41 \pm 10.85$ \\
\hline $8-12$ year & $79.58 \pm 12.63$ & $81.65 \pm 10.72$ & $85.53 \pm 11.18$ & $74.76 \pm 14.41$ & $80.65 \pm 10.73$ & $80.28 \pm 10.19$ \\
\hline 13-18 year & $78.30 \pm 11.96$ & $85.28 \pm 9.31$ & $93.33 \pm 9.70$ & $82.50 \pm 13.2$ & $87.04 \pm 9.07$ & $84.00 \pm 8.03$ \\
\hline$F\left(x^{2}\right)$ & $3.78^{*}$ & 3.16 & 2.32 & $32.11^{*}$ & 5.53 & $13.36^{*}$ \\
\hline$P$ & 0.287 & 0.024 & 0.074 & $<0.001$ & 0.001 & 0.004 \\
\hline \multicolumn{7}{|c|}{ Household registration place } \\
\hline Hangzhou & $85.24 \pm 13.48$ & $86.43 \pm 11.96$ & $89.49 \pm 11.04$ & $84.14 \pm 14.58$ & $86.69 \pm 11.08$ & $86.18 \pm 11.13$ \\
\hline Other cities & $75.88 \pm 12.01$ & $81.68 \pm 10.42$ & $83.94 \pm 11.74$ & $77.52 \pm 14.38$ & $81.05 \pm 10.2$ & $79.25 \pm 9.14$ \\
\hline$t$ & 9.37 & 5.42 & 6.21 & 5.81 & 6.72 & 8.73 \\
\hline$P$ & $<0.001$ & $<0.001$ & $<0.001$ & $<0.001$ & $<0.001$ & $<0.001$ \\
\hline \multicolumn{7}{|l|}{ Household types } \\
\hline Urban areas & $81.96 \pm 13.72$ & $84.66 \pm 11.59$ & $87.28 \pm 11.82$ & $82.23 \pm 14.56$ & $84.72 \pm 10.95$ & $83.76 \pm 10.89$ \\
\hline Rural areas & $78.11 \pm 13.06$ & $83.08 \pm 11.27$ & $85.96 \pm 11.33$ & $78.02 \pm 15.22$ & $82.35 \pm 11.12$ & $80.88 \pm 10.35$ \\
\hline$t$ & 3.31 & 1.56 & 1.28 & 3.24 & 2.45 & 3.05 \\
\hline$P$ & 0.001 & 0.119 & 0.201 & 0.001 & 0.015 & 0.002 \\
\hline \multicolumn{7}{|c|}{ Family monthly income per capita } \\
\hline$<¥ 5000$ & $79.42 \pm 13.79$ & $83.44 \pm 10.95$ & $86.46 \pm 11.69$ & $81.77 \pm 13.55$ & $83.89 \pm 10.32$ & $82.33 \pm 10.26$ \\
\hline$<¥ 5000-¥ 10,000$ & $79.72 \pm 12.82$ & $83.53 \pm 11.78$ & $85.6 \pm 11.69$ & $78.71 \pm 15.69$ & $82.61 \pm 11.48$ & $81.61 \pm 10.74$ \\
\hline$>¥ 10,000$ & $88.04 \pm 13.08$ & $88.17 \pm 11.68$ & $91.49 \pm 10.68$ & $85.1 \pm 15.18$ & $88.25 \pm 10.91$ & $88.18 \pm 11.08$ \\
\hline$F\left(X^{2}\right)$ & 17.81 & $14.352^{*}$ & 20.343 & $15.451^{*}$ & $20.405^{*}$ & 15.26 \\
\hline P & $<0.001$ & 0.001 & $<0.001$ & $<0.001$ & $<0.001$ & $<0.001$ \\
\hline
\end{tabular}

${ }^{*} \chi^{2}$ of Kruskal-Wallis $H$ test 


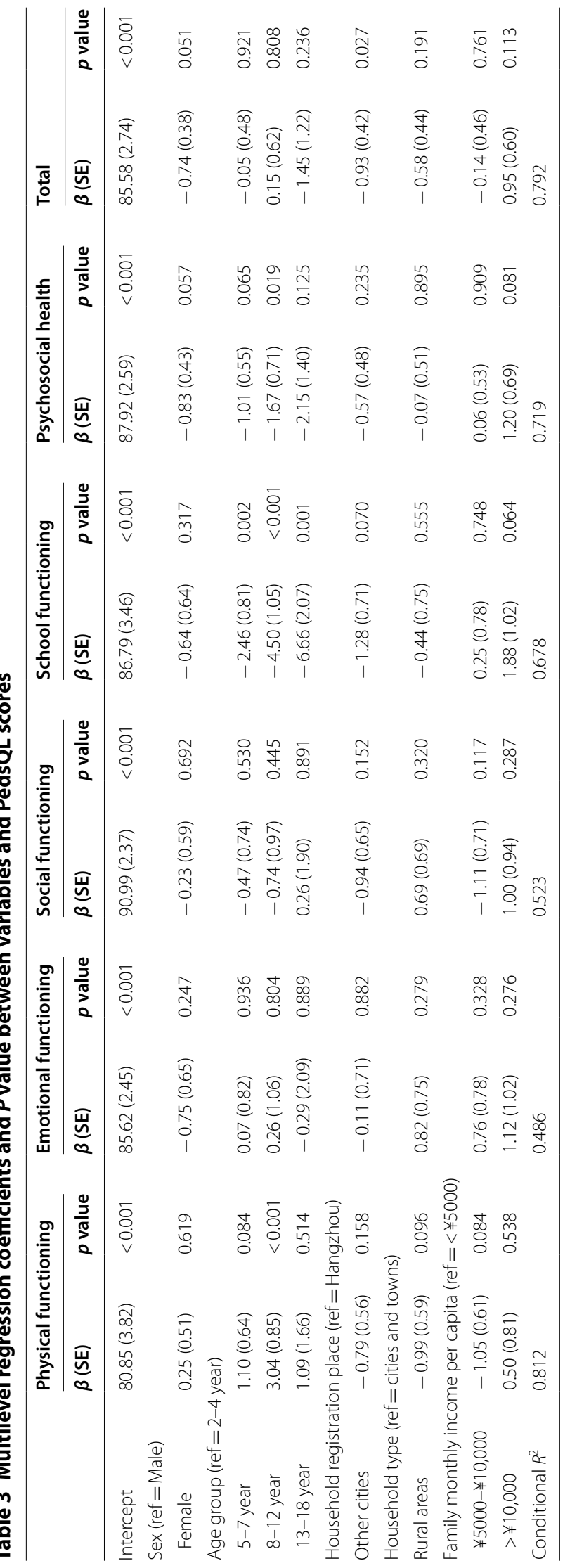


subjective domains such as emotional and social functioning [23, 34-36]. Collins et al. pointed out that parentproxy questionnaires may potentially reduce the accuracy of children's experience [37]. Most authors agree that parent-proxy report should be used as a supplement to child self-report as a secondary outcome measure [15].

The present study demonstrated that PDA had the lowest score in the physical functioning, ITP scored the lowest in the emotional functioning, social functioning, school functioning, psychosocial health and total score. ITP is an acquired autoimmune disease associated with some symptoms, such as spontaneous bruising, mucosal bleeding, epistaxis, and even fatal bleeding events [32]. The low quality of life of ITP may be associated with incessant worries of unpredictable bleeding, fears of invasive procedures, and risk of splenectomy. Additionally, the serious side effects of corticosteroid therapy and daily life restrictions may worsen it [38, 39]. Sood et al. summarized that the average scores of physical functioning, psychosocial health and total score measured by parent proxy-report version of PedsQL ${ }^{\mathrm{TM}}$ 4.0 for 11-18 year patients with Hirschsprung disease were $89.17(\mathrm{SD}=14.40), 82.53(\mathrm{SD}=17.61)$ and 84.84 $(\mathrm{SD}=14.91)$, respectively [8], which were higher the results revealed by the current study and Collins [37] who reported that the psychosocial health score of children with Hirschsprung disease aged between 2 and 10 years $($ mean $=76.0)$ was significantly less than the healthy control group $($ mean $=81.2)$. Kwon et al. reported that the average scores of physical functioning, emotional functioning, social functioning, school functioning and total score measured by parent proxy-report version of PedsQL ${ }^{\mathrm{TM}} 4.0$ of patients with Repaired tetralogy of fallot from 8.4 to 18.7 years old were $78.00(\mathrm{SD}=19.30), 76.00$ $(\mathrm{SD}=17.60), 73.00(\mathrm{SD}=22.40), 73.50(\mathrm{SD}=17.90)$ and $77.40(\mathrm{SD}=15.00)$, respectively [40], which were significantly lower than the normal group except the emotional functioning score, and the total score was very close to the present study. Collett et al. found that the scores of physical functioning and psychosocial health of children with Orofacial Clefts were $85.68(\mathrm{SD}=17.57)$ and $81.03(\mathrm{SD}=15.20)$, which were lower than the results of this study, and negligible differences were found in psychosocial outcomes between children with and without orofacial clefts [41]. Storch et al. reported that the average scores of physical functioning, emotional functioning, social functioning, school functioning, psychosocial health and total score measured by parent proxy-report version of PedsQL ${ }^{\mathrm{TM}} 4.0$ of patients aged from 3 to 25 years with Glycogen storage disease Type I were 76.45 $(\mathrm{SD}=19.63), 76.93(\mathrm{SD}=19.24), 74.23(\mathrm{SD}=20.33), 71.92$ $(\mathrm{SD}=18.28), 74.36(\mathrm{SD}=15.07)$ and $74.88(\mathrm{SD}=15.64)$, respectively, which were all lower than that of the current study except for the physical functioning score [14], and the healthy control sample was significantly higher than the GSD sample in these domains.

HRQoL is a broad multidimensional concept influenced by numerous factors. The results of multilevel linear regression showed that children at the age of 8-12 reported higher physical functioning scores and less psychosocial health scores than children who at the age of 2-4. Although there was no significant difference among the $13-18$ age group, 5-7 age group and 2-4 age group, the regression coefficients indicated that the score of psychosocial health decreased with age. Collins et al. reported a similar result that psychosocial functioning in the children with Hirschsprung disease was negatively affected by increasing age [37]. Peer teasing has been shown to be a strong predictor of self-concept and parent-reported behavior problems [42]. Collett et al.found that many pre-school children with Orofacial clefts are quite resilient, despite the potential for social stigmatization. However, as children develop and peer groups become more important, this situation may become more difficult to maintain [41]. This study also showed that increasing age negatively affected school functioning scores. Miatton et al.revealed that children with Tetralogy of fallot showed significantly lower scores on the school performances than healthy peers [43]. Roodbol et al. reported that many children were held back in class or dropped out of school after developing Guillain-Barré syndrome [44]. Khalil found that age at the time of surgery was negatively affecting school functioning ( $\beta=-0.907)$ in children with Hirschsprung's disease [45]. The results of the multivariate analysis show that gender was not an influencing factor of HRQol. Though Mills et al. found that girls with Hirschsprung's disease had higher scores across all HRQol scales, the difference was not significant [33]. Many previous studies also indicated that gender did not have a significant effect on aspects of the global HRQol in children with Hirschsprung's disease $[8,37,45]$. The total score of children whose household registration place was in Hangzhou was significantly higher than that in other cities, which is likely to be the provincial capital city with the highest per capita GDP, representing a higher socio-economic status, where children have access to better medical services and education, and develop positive coping mechanisms to cope with adversity. Moreover, Damiano et al. reported that in families with higher income, patients with Cleft lip and palate had better physical, psychosocial, and total health scores [46].

A 2016 study investigated 1771 patients covered with 142 rare diseases in China. According to the study, $66 \%$ of the patients had been misdiagnosed before, and the most serious problem in the course of treatment was high 
medical cost (32.07\%).Other problems were few types of drugs and rehabilitation (15.81\%), poor treatment effect (12.25\%), low reimbursement rate (12.14\%), poor accessibility to health service (11.80\%), respectively [47]. Among the 121 rare diseases listed in China's First List of Rare Diseases, 9 rare diseases have no medication, and the related medications of 13 rare diseases are excluded from the coverage of medical insurance [48]. Another study revealed similar results to the present study that the reimbursement rate of medical insurance was between 10 to $50 \%$, and $80 \%$ of patients did not have commercial insurance [49]. Therefore, the Chinese government should strengthen its support to carry out fundamental research on the treatment and drugs of rare diseases, and formulate and implement incentive policies for the production or importation of orphan drugs. Moreover, it is recommended to include more rare disease drugs in medical insurance and raise the reimbursement rate to enhance orphan drug availability and reduce the financial burden of rare diseases.

\section{Limitations}

Some limitations of the study should be considered. First, we did not inquire about the age at onset of symptoms or age at diagnosis. Although most of the literature did not take the age at onset of symptoms or age at diagnosis as an influencing factor, we still believe that this is one of the limitations of our study. Second, the research team did not confirm the diagnosis through a manual chart review, and there may be misdiagnosis. Third, since there were only 18 subjects in the 13-18 age group, this may be underrepresented in our sample. Fourth, according to the information we collected, among the 11 rare diseases included in the study, only PDA, Polysyndactyly, Cleft lip and palate can be cured by surgery, and the rest are treated with symptomatic support or no treatment. There is no denying that different treatments and prognosis will affect the quality of life. If patients with rare diseases can be cured by surgery, their quality of life will theoretically be improved in the long run. For most rare diseases that lack specific treatment, the improvement of quality of life by general supportive treatment requires further scientific evaluation. However, since we did not investigate information about treatment and prognosis, we are unable to provide evidence of the effect of treatment on the quality of life of rare diseases, which will be the direction of our future efforts.

\section{Conclusions}

This study revealed that the HRQoL of children with ITP was relatively lower compared with other rare diseases. We should pay more attention to the children's mental health and school functioning with age.
Patients still face a lot of problems when seeking treatment, such as a lack of effective medicine and unable to afford medical expenses. Therefore, further measures should be adopted to improve the efficiency of diagnosis and the effect of treatment, to improve the availability of health services, and to alleviate the economic burden.

\section{Abbreviations \\ HRQoL: Health-related quality of life; PedsQ $L^{\mathrm{TM}}{ }^{\text {: }}$ : Pediatric quality of life inven- tory ${ }^{\mathrm{TM}}$; LSD: Least significant difference; ITP: Autoimmune thrombocytopenia; PDA: Patent ductus arteriosus; GSD: Glycogen storage disease. \\ Acknowledgements \\ We would like to thank all participants for their time. \\ Authors' contributions \\ XW and JR participated in the design of the study. SW collected and processed the data. QG performed the statistical analysis and drafted the manuscript. All authors read and approved the final manuscript. \\ Funding \\ This study was supported by Zhejiang Province Public Welfare Technology Application Research Project (CN), Grant No. 2015 C33145.}

Availability of data and materials

Please contact author for data requests.

\section{Ethics approval and consent to participate}

The respondents were anonymous, voluntary and consent for participation. All study procedures were approved by the Ethics Committee of Hangzhou Medical College.

\section{Consent for publication}

Not applicable.

\section{Competing interests}

The authors declare that they have no competing interests.

\section{Author details}

${ }^{1}$ Department of Public Health, Hangzhou Medical College, No. 481 Binwen Road, Hangzhou 310053, Zhejiang Province, China. ${ }^{2}$ Department of Health Management, School of Medicine, Hangzhou Normal University, No. 2318 Yuhangtang Road, Hangzhou 311121, Zhejiang Province, China. ${ }^{3}$ Center for Medical Science, Technology and Education of Zhejiang Province, No, 60 Hefang Street, Hangzhou 310006, Zhejiang Province, China.

Received: 20 March 2020 Accepted: 21 September 2020 Published online: 23 November 2020

References

1. Melnikova I. Rare diseases and orphan drugs. Nat Rev Drug Discov. 2012:11:267-8.

2. Richter T, Nestler-Parr S, Babela R, Khan ZM, Tesoro T, Molsen E, et al. Rare disease terminology and definitions - a systematic global review: report of the ISPOR rare disease special interest group. Value Health. 2015:18(6):906-14.

3. Ma D, Li DG, Zhang X, He L. Opportunities and challenges in the prevention and treatment of rare diseases in China (in Chinese). Chin J Evid Based Pediatr. 2011;6:81-2.

4. Abbott A. Rare-disease project has global ambitions. Nature. 2011;472(7341):17. 
5. Stevens S, Miller N, Rashbass J. development and progress of the national Congenital anomaly and rare disease registration service. Arch Dis Child. 2018;103(3):215-7.

6. He JJ, Song P, Kang Q, Zhang X, Hu JH, Yang Y, et al. Overview on social security system of rare diseases in China. Bioscience Trends. 2019;13(4):314-23.

7. Schieppati A, Henter Jl, Daina E, Aperia A. Why rare diseases are an important medical and social issue. Lancet. 2008;371(9629):2039-41.

8. Sood S, Lim R, Collins L, Trajanovska M, Hutson JM, Teague WJ, et al. The long-term quality of life outcomes in adolescents with Hirschsprung disease. J Pediatr Surg. 2018;53(12):2430-4.

9. Rajmil L, Perestelo-Pérez L, Herdman M. Quality of life and rare diseases. Adv Exp Med Biol. 2010;686:251-72

10. Varni JW, Burwinkle TM, Seid M, Skarr D. The PedsQL ${ }^{\mathrm{TM} *} 4.0$ as a pediatric population health measure: feasibility, reliability, and validity. Ambul Pediatrics. 2003;3(6):329-41.

11. Rudolph T, Larsen JP, Farbu E. The long-term functional status in patients with Guillain-Barré syndrome. Eur J Neurol. 2008;15(12):1332-7.

12. Aslan Bl, Gülsen A, Tirank SB, Findikçioglu K, Uzuner FD, Tutar H, et al. Family functions and life quality of parents of children with cleft lip and palate. J Craniofac Surg. 2018;29(6):1614-8.

13. Tran VQ, Mahler T, Dassonville M, Truong DQ, Robert A, Goyens P, et al. Long-term outcomes and quality of life in patients after soave pull-through operation for Hirschsprung's disease: an observational retrospective study. Eur J Pediatr Surg. 2018;28(05):445-54.

14. Storch E, Keeley M, Merlo L, Jacob M, Correia C, Weinstein D. Psychosocial functioning in youth with glycogen storage disease type I. J Pediatr Psychol. 2008:33(7):728-38

15. Sluys KP, Lannge M, Iselius L, Eriksson LE. Six years beyond pediatric trauma: child and parental ratings of children's health-related quality of life in relation to parental mental health. Qual Life Res. 2015;24(11):2689-99.

16. Orphanet. Search for a rare disease [Internet]. https://www.orpha.net/conso r/cgi-bin/Disease_Classif.php?lng=EN. Cited 03-15-2018.

17. Varmi JW, Seid M, Kurtin P. PedsQL ${ }^{\mathrm{TM}} 4.0$ : Reliability and validity of the Pediatric Quality of Life Inventory ${ }^{\mathrm{TM}}$ Version 4.0 Generic Core Scales in healthy and patient populations. Med Care. 2001:39:800-12.

18. Reinfjell T, Diseth $T H$, Veenstra M, Vikan A. Measuring health-related quality of life in young adolescents: Reliability and validity in the Norwegian version of the Pediatric Quality of Life Inventory ${ }^{\mathrm{TM}} 4.0$ (PedsQL) generic core scales. Health Qual Life Outcomes. 2006;4(1):61.

19. Varni JW, Limbers CA. The Pediatric Quality of Life Inventory: measuring pediatric health-related quality of life from the perspective of children and their parents. Pediatr Clin North Am. 2009:56:843-63.

20. Berkes A, Pataki I, Kiss M, Kemény C, Kardos L, Varni JW, et al. Measuring health-related quality of life in Hungarian children with heart disease: psychometric properties of the Hungarian version of the Pediatric Quality of Life Inventory ${ }^{\mathrm{TM}} 4.0$ Generic Core Scales and the Cardiac Module. Health Qual Life Outcomes. 2010;8(1):14

21. Engelen V, Haentjens MM, Detmar SB, Koopman HM, Grootenhuis MA. Health related quality of life of Dutch children: psychometric properties of the PedsQL in the Netherlands. BMC Pediatr. 2009;9(1):68.

22. Sheldrick RC, Neger EN, Shipman D, Perrin EC. Quality of life of adolescents with autism spectrum disorders: Concordance among adolescents' self-reports, parents'reports, and parents' proxy reports. Qual Life Res. 2012;21(1):53-7.

23. Eiser C, Morse R. Can parents rate their child's health-related quality of life? Results of a systematic review. Qual Life Res. 2001;10(4):347-57.

24. Varni JW, Limbers CA, Burwinkle TM. Parent proxy-report of their children's health-related quality of life: an analysis of 13,878 parents' reliability and validity across age subgroups using the PedsQ $L^{\mathrm{TM}} 4.0$ Generic Core Scales. Health Quality Life Outcomes. 2007;5(1):2.

25. Mussatto K. Adaptation of the child and family to life with a chronic illness. Cardiol Young. 2006;16(S3):110-6.

26. Chan LF, Chow SM, Lo SK. Preliminary validation of the Chinese version of the pediatric quality of life inventory. Int J Rehabil Res. 2005;28(3):219-27.

27. Chen YM, He LP, Mai JC, Hao YT, Xiong LH, Chen WQ, WU JN. Validity and reliability of pediatric quality of life inventory version 4.0 generic core scales in Chinese children and adolescents. Zhonghua Liu Xing Bing Xue Za Zhi. 2008:29:560-3.

28. Huang Y, Zhong XN, Li QY, Xu D, Zhang XL, Feng C, et al. Health-related quality of life of the rural-China left-behind children or adolescents and influential factors: a cross-sectional study. Health Qual Life Outcomes. 2015;13(1):29.
29. Wu H, Li H, Gao Q. Psychometric properties of the Chinese version of the pediatric quality of life inventory 4.0 Generic core scales among children with short stature. Health Qual Life Outcomes. 2013;11(1):87.

30. JiY, Chen S, Li K, Xiao N, Yang X, Zheng S, et al. Measuring health-related quality of life in children with cancer living in Mainland China: feasibility, reliability and validity of the Chinese Mandarin version of PedsQL 4.0 Generic Core Scales and 3.0 Cancer Module. Health Qual Life Outcomes. 2011;9(1):103.

31. Sundaram SS, Alonso EM, Haber B, Magee JC, Fredericks E, Kamath B, et al. Health related quality of life in patients with biliary atresia surviving with their native liver. J Pediatr. 2013;163(4):1052-7.

32. Zhang H, Wang L, Quan M, Huang J, Wu P, Lu Q, et al. Health-related quality of life in children with chronic immune thrombocytopenia in China. Health Qual Life Outcomes. 2016;14(1):45.

33. Mills JLA, Konkin DE, Milner R, Penner JG, Langer M, Webber EM. Long-term bowel function and quality of life in children with Hirschsprung's disease. J Pediatr Surg. 2008;43(5):899-905.

34. Achenbach TM, McConaughy SH, Howell CT. Child/adolescent behavioral and emotional problems: Implications of cross-informant correlations for situational specificity. Psychol Bull. 1987;101(2):213-32.

35. Theunissen NCM, Vogels TGC, Koopman HM, Verrips GHW, Zwinderman KAH, Verloove-Vanmhorick SP, et al. The proxy problem: Child reports versus parent report in health-related quality of life research. Qual Life Res. 1998;7(5):387-97.

36. Krol Y, Grootenhuis MA, DestrÉe-Vonk A, Lubbers LI, Koopman HM, Last $B F$. Health related quality of life in children with congenital heart disease. Psychol Health. 2003;18(2):251-60.

37. Collins L, Collis B, Trajanovska M, Khanal R, Hutson JM, Teague W, et al. Quality of life outcomes in children with Hirschsprung disease. J Pediatr Surg. 2017:52(12):2006-10.

38. Neunert CE, Buchanan GR, Blanchette V, Barnard D, Young NL, Curtis $C$, et al. Relationships among bleeding severity, health-related quality of life, and platelet count in children with immune thrombocytopenic purpura. Pediatric Blood Cancer. 2009;53(4):652-4.

39. Michel M. Immune thrombocytopenic purpura: epidemiology and implications for patients. Eur J Haematol. 2009;82:3-7.

40. Kwon EN, Mussatto K, Simpson PM, Brosig C, Nugent M, Samyn MM. Children and adolescents with repaired tetralogy of fallot report quality of life similar to healthy peers. Congenital Heart Dis. 2011;6(1):18-27.

41. Collett BR, Cloonan YK, Speltz ML, Anderka M, Werler MM. Psychosocial functioning in children with and without orofacial clefts and their parents. Cleft Palate-Craniofac J. 2012:49(4):397-405.

42. Hunt O, Burden D, Hepper P, Stevenson M, Johnston C. Parent reports of the psychosocial functioning of children with cleft lip and/or palate. Cleft Palate-Craniofac J. 2007:44(3):304-11.

43. Miatton M, De Wolf D, François K, Thiery E, Vingerhoets G. Intellectual, neuropsychological, and behavioral functioning in children with tetralogy of Fallot. J Thoracic Cardiovasc Surg. 2007;133(2):449-55.

44. Roodbol J, de Wit MCY, Aarsen FK, Catsman-Berrevoets CE, Jacobs BC. Longterm outcome of Guillain-Barré syndrome in children. J Peripheral Nervous Syst. 2014;19(2):121-6.

45. Khalil M. Long-term health-related quality of life for patients with Hirschsprung's disease at 5 years after transanal endorectal pull-through operation. Qual Life Res. 2015;24(11):2733-8.

46. Damiano PC, Tyler MC, Romitti PA, Momany ET, Jones MP, Canady JW, et al. Health-related quality of life among preadolescent children with oral clefts: the mother's perspective. Pediatrics. 2007;120(2):e283-90.

47. Ma Z, Zheng XY. Analysis of the health service utilization among patients with rare diseases and the influencing factors in China (in Chinese). Chin J Health Policy. 2018;11(11):60-4.

48. Shao WB, LiYY, Wang F, Zhu YJ, Xiao L, Huang RF. The current situation and suggestions on orphan drug availability in China (in Chinese). Food Drug Adm Mag. 2019;181(02):10-7.

49. Wang $\mathrm{P}$, Zhang YF. On the coping strategies of rare diseases in Britain and its enlightenment to China (in Chinese). Med Jurisprud. 2016;8(2):70-5.

\section{Publisher's Note}

Springer Nature remains neutral with regard to jurisdictional claims in published maps and institutional affiliations. 